\title{
Traumatic Brain Injury, Microglia, and Beta Amyloid
}

\author{
Rebekah C. Mannix ${ }^{1,2}$ and Michael J. Whalen ${ }^{2,3}$ \\ ${ }^{1}$ Division of Emergency Medicine, Department of Medicine, Children's Hospital Boston, Harvard Medical School, Boston, MA 02124, \\ USA \\ ${ }^{2}$ Neuroscience Center, Massachusetts General Hospital, Harvard Medical School, Charlestown, MA 02129, USA \\ ${ }^{3}$ Department of Pediatrics, Massachusetts General Hospital, Harvard Medical School, Charlestown, MA 02129, USA
}

Correspondence should be addressed to Rebekah C. Mannix, rebekah.mannix@childrens.harvard.edu

Received 30 November 2011; Accepted 2 March 2012

Academic Editor: Joseph El Khoury

Copyright (C) 2012 R. C. Mannix and M. J. Whalen. This is an open access article distributed under the Creative Commons Attribution License, which permits unrestricted use, distribution, and reproduction in any medium, provided the original work is properly cited.

Recently, there has been growing interest in the association between traumatic brain injury (TBI) and Alzheimer's Disease (AD). TBI and AD share many pathologic features including chronic inflammation and the accumulation of beta amyloid (A $\beta$ ). Data from both $\mathrm{AD}$ and $\mathrm{TBI}$ studies suggest that microglia play a central role in $\mathrm{A} \beta$ accumulation after TBI. This paper focuses on the current research on the role of microglia response to $\mathrm{A} \beta$ after TBI.

\section{Introduction}

Recently, there has been growing interest in the association between traumatic brain injury (TBI) and Alzheimer's Disease $(\mathrm{AD})$. The interest grew from several lines of evidence, including epidemiological studies that demonstrated an association of TBI and the development of AD later in life [17] and autopsy studies that showed acute and chronic ADlike pathology in TBI victims $[8,9]$. While most of the studies investigating the association of $\mathrm{AD}$ and TBI have focused on the accumulation and clearance amyloid- $\beta(\mathrm{A} \beta)[2,8,9]$, chronic neuroinflammation is also a common feature of AD and TBI, and microglia likely play a central role $[10,11]$. In $\mathrm{AD}$, microglia are recruited to newly formed $\mathrm{A} \beta$ plaques, where microglial activation functions as a double-edged sword, promoting beneficial responses such as $A \beta$ clearance [12-14] while also eliciting a proinflammatory response [12]. Similar patterns of microglia activation have been demonstrated both acutely and chronically after TBI $[15,16]$.

This paper will explore the current research on the role of microglia response to $\mathrm{A} \beta$ after TBI. Although there are few studies that directly examine microglial reaction to traumainduced $\mathrm{A} \beta$, data from TBI and $\mathrm{AD}$ experimental and human studies will be used to make an argument for a central role of microglia in acute and chronic responses to $\mathrm{A} \beta$-mediated secondary injury after TBI.

\section{General Microglial Response after TBI}

TBI is a disease process in which mechanical injury initiates cellular and biochemical changes that perpetuate neuronal injury and death over time, a process known as secondary injury. Secondary injury begins minutes after injury and can continue years after the initial insult. Mechanisms implicated in secondary injury after TBI include glutamate excitotoxicity, blood-brain barrier disruption, secondary hemorrhage, ischemia, mitochondrial dysfunction, apoptotic and necrotic cell death, and inflammation [17].

As the primary mediators of the brain's innate immune response to infection, injury, and disease, microglia react to injury within minutes. In fact, microglia may represent the first line of defense following injury [18]. Microglial activation has been demonstrated as early as 72 hours after injury in human TBI victims and can persist for years after injury $[15,16,19,20]$. Experimental models have recapitulated these findings, with chronic microglial activation being demonstrated weeks to months after injury [21-24].

Gene-profiling studies also strongly implicate early microglial activation after TBI.

Markers of microglial activation (CD68, MHC-II), stress responses (p22phox, heme oxygenase 1), and chemokine expression (CXCL10, CXCL6) have been shown to markedly increase after experimental models of TBI [25]. Consistent 


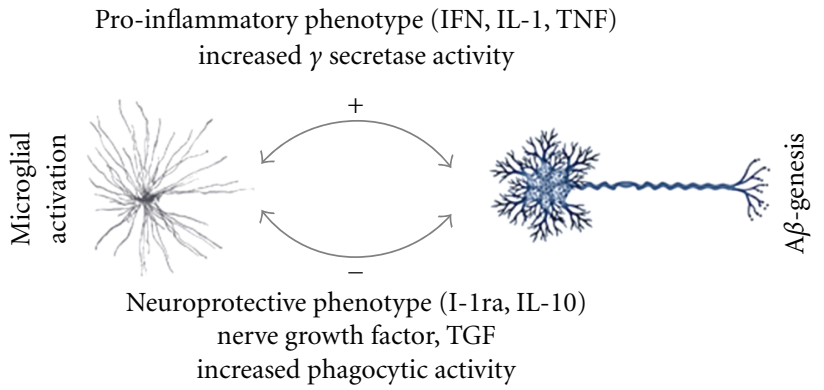

Figure 1: Schematic depiction of the beneficial and detrimental effects of the interaction $\mathrm{A} \beta$-genesis and microglia after traumatic brain injury.

with early microglial activation after injury, experimental models have demonstrated rapid increases in expression of both IL- $1 \beta$ and TNF- $\alpha$ after injury $[26,27]$. Much of this proinflammatory cascade may be mediated by Il-1IR, which is strongly expressed on microglia [27-29]. In addition to proinflammatory cytokines, activated microglia also produce other neurotoxic products after injury such as nitric oxide (NO) and superoxide free radicals that generate reactive oxygen species (ROS) and reactive nitrogen species (RNS).

Microglia also produce a number of neuroprotective substances after injury, including anti-inflammatory cytokines (IL-10, IL-1 receptor antagonist (Il-1ra)) and neurotrophic factors (nerve growth factor, transforming growth factor $\beta$ (TGF- $\beta$ ). IL-10, which is elevated acutely after injury in humans [30], has been shown to have beneficial effects in experimental models of injury [31]).

These neuroprotective effects may be a result of suppressed microglial production of proinflammatory cytokines $[31,32]$. TGF- $\beta$ also has also been shown to have neuroprotective effects after injury, including improved function, decreased lesion size, and decreased iNOS production $[33,34]$.

\section{Microglial Response to $\mathrm{A} \beta$ after TBI}

$\mathrm{A} \beta$, which is elevated acutely after TBI, may be a key mediator of microglial activation in this setting [35]. In autopsy studies, $\mathrm{A} \beta$ plaques, a hallmark of $\mathrm{AD}$, were present in as many as $30 \%$ of TBI victims (including children) $[8,9]$. The plaques found in TBI patients, which are strikingly similar to those observed in the early stages of $\mathrm{AD}$, develop rapidly and can appear within a few hours after injury $[9,36]$. TBIinduced increases in $\mathrm{A} \beta$ have been successfully replicated in animal models of brain trauma [37-40]. Moreover, A $\beta$ accumulation after TBI has also been shown to be associated with increases in the enzymes necessary for $\mathrm{A} \beta$-genesis, including BACE1 protein ( $\beta$-secretase) and the gamma secretase complex proteins [41-43].

Microglia may have a dual role in $\mathrm{A} \beta$ accumulation and clearance (Figure 1). Following closed head injury, microglia have been shown to have increased expression of the gamma secretase complex proteins, suggesting a role for microglia in posttraumatic $\mathrm{A} \beta$-genesis [43]. Polymorphisms in the $\mathrm{A} \beta$-degrading enzyme neprilysin have been shown to affect rates of $\mathrm{A} \beta$ accumulation after TBI [2], suggesting the possi- bility that changes in microglial neprilysin expression may be a pathologic mechanism in post-TBI $A \beta$ accumulation in addition to the known relevance to AD [12]. Moreover, proinflammatory cytokines expressed by microglia, including interferon- $\gamma$, interleukin- $1 \beta$, and tumor necrosis factor- $\alpha$, can specifically stimulate gamma-secretase activity, concomitant with increased production of $\mathrm{A} \beta$ and the intracellular domain of APP (AICD) [44]. Further evidence suggests that increases in the numbers of neurons with elevated B-APP concentrations after TBI correlate with increases in the number of activated microglia expressing IL- $1 \alpha$ and that clusters of dystrophic neurites containing B-APP are nearly universally associated with activated microglia expressing IL$1 \alpha$ [45]. Microglia containing $\mathrm{A} \beta$ have also been described in association with TBI-induced $\mathrm{A} \beta$ plaques, suggesting that phagocytic clearance of plaques may occur [46].

In addition to the temporospatial relationship of microglial and $\mathrm{A} \beta$ after TBI, much of the evidence regarding the important role of microglia in the modulation of TBIinduced $\mathrm{A} \beta$ is indirect. Most of this indirect evidence is derived from drug studies, which, while not designed to demonstrate the important interaction of microglial with TBI-induced $\mathrm{A} \beta$, have served to demonstrate this vital interaction. Many of the studies that have indirectly elucidated the interaction of microglia and $\mathrm{A} \beta$ after TBI have focused on therapeutics targeting postinjury inflammation. Minocycline, a compound whose anti-inflammatory properties (including attenuating microglial activation) have been widely demonstrated in different models of TBI [47, 48], has also been shown to preclude formation of $\mathrm{A} \beta$ through restoration of the nonamyloidogenic $\alpha$-secretase pathway of APP processing [49]. Interestingly, it has been shown that some other anti-inflammatory compounds that exert neuroprotective effects in TBI, such as nonsteroidal anti-inflammatory drugs, cholesterol-lowering drugs, and steroid hormones, also enhance the $\alpha$-secretase pathway [50-53]. It is unclear from these studies whether the anti-inflammatory and pro $\alpha$ secretase effects are merely parallel processes, although certainly diversion of APP from the production of $\mathrm{A} \beta$, which has known proinflammatory properties including stimulation of microglial activation, may itself adequately explain both the anti inflammatory and anti amyloidogentic effects.

Additional studies support the observation that suppression of microglial activation after TBI is also associated with decreases in injury-induced $\mathrm{A} \beta$. Apoe mimetic peptides, liver $\mathrm{X}$-receptor (LXR) agonists, and 3-Hydroxy-3-methylglutaryl coenzyme A reductase inhibitors (statins) have all been shown to attenuate microglial activation and mitigate increases in A $\beta$ after TBI [54-56]. It should be noted, however that none of these earlier studies can definitively lead one to conclude whether $\mathrm{A} \beta$ is a cause, product, or mere marker of microglial activation and secondary injury after TBI. However, what can be concluded is that $\mathrm{A} \beta$ is an excellent indicator of microglial activation following TBI.

\section{Conclusions and Future Directions}

The link between trauma, microglial activation, and $\mathrm{A} \beta$ is likely to be extremely complex, and work in this field remains 
in its infancy. Much of the work is derived from studies in $\mathrm{AD}$, though the time course and long-term sequelae of $\mathrm{TBI}$ and $\mathrm{AD}$ may require separate lines of investigation. One recurring issue is the role of $\mathrm{A} \beta$ in the pathogenesis of microglial activation after brain injury which parallels the increasing emphasis on microglial function in the pathogenesis of AD.

Prior studies in $\mathrm{AD}$ suggest that microglial clearance of $\mathrm{A} \beta$ declines with aging [12]. It is therefore important to understand how TBI-induced $\mathrm{A} \beta$ alters long-term microglial function and $A \beta$-clearance. Future work should focus on whether blocking $\mathrm{A} \beta$-genesis after TBI alters short- and long-term microglial activation. In addition, therapeutics targeting microglial-mediated $\mathrm{A} \beta$ clearance, such as the new $\mathrm{AD}$ therapeutic bexarotene [57], may hold promise as new modalities to treat TBI patients.

In this paper, we have attempted to show how a mechanistic understanding of the interaction of $\mathrm{A} \beta$ and microglia after TBI could have significant implications for therapeutics, especially for those at the highest risk for TBI, including those in the military and those who engage in contact sports. Furthermore, the advancement of drug discoveries in the field of TBI, such as sex steroids or Apoe mimetics which alter both microglial function and $\mathrm{A} \beta$ metabolism, may have potentially important roles in TBI as well as other neurodegenerative diseases. Finally, as we advance our mechanistic understanding of the interaction between microglia and $\mathrm{A} \beta$ after TBI, it is important to understand whether therapeutic interventions targeting microglia and $\mathrm{A} \beta$ will have any effect on long-term cognitive sequelae in TBI victims.

\section{References}

[1] V. E. Johnson, W. Stewart, and D. H. Smith, "Traumatic brain injury and amyloid- $\beta$ pathology: a link to Alzheimer's disease?" Nature Reviews Neuroscience, vol. 11, no. 5, pp. 361-370, 2010.

[2] V. E. Johnson, W. Stewart, D. I. Graham, J. E. Stewart, A. H. Praestgaard, and D. H. Smith, "A neprilysin polymorphism and amyloid- $\beta$ plaques after traumatic brain injury," Journal of Neurotrauma, vol. 26, no. 8, pp. 1197-1202, 2009.

[3] J. A. Mortimer, L. R. French, J. T. Hutton, and L. M. Schuman, "Head injury as a risk factor for Alzheimer's disease," Neurology, vol. 35, no. 2, pp. 264-267, 1985.

[4] A. B. Graves, E. White, T. D. Koepsell et al., "The association between head trauma and Alzheimer's disease," American Journal of Epidemiology, vol. 131, no. 3, pp. 491-501, 1990.

[5] J. A. Mortimer, C. M. van Duijn, V. Chandra et al., "Head trauma as a risk factor for Alzheimer's disease: a collaborative re-analysis of case-control studies. EURODEM Risk Factors Research Group," International Journal of Epidemiology, vol. 20, supplement 2, pp. S28-S35, 1991.

[6] E. Salib and V. Hillier, "Head injury and the risk of Alzheimer's disease: a case control study," International Journal of Geriatric Psychiatry, vol. 12, pp. 363-368, 1997.

[7] Z. Guo, L. A. Cupples, A. Kurz et al., "Head injury and the risk of AD in the MIRAGE study," Neurology, vol. 54, no. 6, pp. 1316-1323, 2000.

[8] G. W. Roberts, S. M. Gentleman, A. Lynch, and D. I. Graham, "ßA4 amyloid protein deposition in brain after head trauma," The Lancet, vol. 338, no. 8780, pp. 1422-1423, 1991.
[9] G. W. Roberts, S. M. Gentleman, A. Lynch, L. Murray, M. Landon, and D. I. Graham, " $\beta$ amyloid protein deposition in the brain after severe head injury: implications for the pathogenesis of Alzheimer's disease," Journal of Neurology Neurosurgery and Psychiatry, vol. 57, no. 4, pp. 419-425, 1994.

[10] M. T. Giordana, A. Attanasio, P. Cavalla, A. Migheli, M. C. Vigliani, and D. Schiffer, "Reactive cell proliferation and microglia following injury to the rat brain," Neuropathology and Applied Neurobiology, vol. 20, no. 2, pp. 163-174, 1994.

[11] W. J. Streit, "The role of microglia in brain injury," NeuroToxicology, vol. 17, no. 3-4, pp. 671-678, 1996.

[12] S. E. Hickman, E. K. Allison, and J. El Khoury, "Microglial dysfunction and defective $\beta$-amyloid clearance pathways in aging alzheimer's disease mice," The Journal of Neuroscience, vol. 28, no. 33, pp. 8354-8360, 2008.

[13] S. Mandrekar, Q. Jiang, C. Y. D. Lee, J. Koenigsknecht-Talboo, D. M. Holtzman, and G. E. Landreth, "Microglia mediate the clearance of soluble a $\beta$ through fluid phase macropinocytosis," The Journal of Neuroscience, vol. 29, no. 13, pp. 4252-4262, 2009.

[14] J. C. M. Schlachetzki and M. Hüll, "Microglial activation in Alzheimer's disease," Current Alzheimer Research, vol. 6, no. 6, pp. 554-563, 2009.

[15] S. Engel, H. Schluesener, M. Mittelbronn et al., "Dynamics of microglial activation after human traumatic brain injury are revealed by delayed expression of macrophage-related proteins MRP8 and MRP14," Acta Neuropathologica, vol. 100, no. 3, pp. 313-322, 2000.

[16] S. M. Gentleman, P. D. Leclercq, L. Moyes et al., "Long-term intracerebral inflammatory response after traumatic brain injury," Forensic Science International, vol. 146, no. 2-3, pp. 97104, 2004.

[17] T. K. McIntosh, K. E. Saatmann, R. Raghupathi et al., "The Dorothy Russell memorial lecture. The molecular and cellular sequelae of experimental traumatic brain injury: pathogenetic mechanisms," Neuropathology and Applied Neurobiology, vol. 24, no. 4, pp. 251-267, 1998.

[18] D. Davalos, J. Grutzendler, G. Yang et al., "ATP mediates rapid microglial response to local brain injury in vivo," Nature Neuroscience, vol. 8, no. 6, pp. 752-758, 2005.

[19] R. Beschorner, T. D. Nguyen, F. Gözalan et al., “CD14 expression by activated parenchymal microglia/macrophages and infiltrating monocytes following human traumatic brain injury," Acta Neuropathologica, vol. 103, no. 6, pp. 541-549, 2002.

[20] A. F. Ramlackhansingh, D. J. Brooks, R. J. Greenwood et al., "Inflammation after trauma: microglial activation and traumatic brain injury," Annals of Neurology, 2011.

[21] E. Csuka, V. H. J. Hans, E. Ammann, O. Trentz, T. Kossmann, and M. C. Morganti-Kossmann, "Cell activation and inflammatory response following traumatic axonal injury in the rat," NeuroReport, vol. 11, no. 11, pp. 2587-2590, 2000.

[22] J. Maeda, M. Higuchi, M. Inaji et al., "Phase-dependent roles of reactive microglia and astrocytes in nervous system injury as delineated by imaging of peripheral benzodiazepine receptor," Brain Research, vol. 1157, no. 1, pp. 100-111, 2007.

[23] J. Gehrmann, "Microglia: a sensor to threats in the nervous system?" Research in Virology, vol. 147, no. 2-3, pp. 79-88, 1996.

[24] M. Koshinaga, Y. Katayama, M. Fukushima, H. Oshima, T. Suma, and T. Takahata, "Rapid and widespread microglial activation induced by traumatic brain injury in rat brain slices," Journal of Neurotrauma, vol. 17, no. 3, pp. 183-192, 2000. 
[25] C. Israelsson, H. Bengtsson, A. Kylberg et al., "Distinct cellular patterns of upregulated chemokine expression supporting a prominent inflammatory role in traumatic brain injury," Journal of Neurotrauma, vol. 25, no. 8, pp. 959-974, 2008.

[26] J. F. Stover, B. Schöning, T. F. Beyer, C. Woiciechowsky, and A. W. Unterberg, "Temporal profile of cerebrospinal fluid glutamate, interleukin-6, and tumor necrosis factor- $\alpha$ in relation to brain edema and contusion following controlled cortical impact injury in rats," Neuroscience Letters, vol. 288, no. 1, pp. 25-28, 2000.

[27] K. T. Lu, Y. W. Wang, J. T. Yang, Y. L. Yang, and H. I. Chen, “Effect of interleukin-1 on traumatic brain injury-induced damage to hippocampal neurons," Journal of Neurotrauma, vol. 22, no. 8, pp. 885-895, 2005.

[28] E. Pinteaux, L. C. Parker, N. J. Rothwell, and G. N. Luheshi, "Expression of interleukin-1 receptors and their role in interleukin-1 actions in murine microglial cells," Journal of Neurochemistry, vol. 83, no. 4, pp. 754-763, 2002.

[29] N. Rothwell, "Interleukin-1 and neuronal injury: mechanisms, modification, and therapeutic potential," Brain, Behavior, and Immunity, vol. 17, no. 3, pp. 152-157, 2003.

[30] E. Csuka, M. C. Morganti-Kossmann, P. M. Lenzlinger, H. Joller, O. Trentz, and T. Kossmann, "IL-10 levels in cerebrospinal fluid and serum of patients with severe traumatic brain injury: relationship to IL- 6 , TNF- $\alpha$, TGF- $\beta 1$ and blood-brain barrier function," Journal of Neuroimmunology, vol. 101, no. 2, pp. 211-221, 1999.

[31] S. M. Knoblach and A. I. Faden, "Interleukin-10 improves outcome and alters proinflammatory cytokine expression after experimental traumatic brain injury," Experimental Neurology, vol. 153, no. 1, pp. 143-151, 1998.

[32] S. G. Kremlev and C. Palmer, "Interleukin-10 inhibits endotoxin-induced pro-inflammatory cytokines in microglial cell cultures," Journal of Neuroimmunology, vol. 162, no. 1-2, pp. 71-80, 2005.

[33] Y. Hamada, T. Ikata, S. Katoh et al., "Effects of exogenous transforming growth factor- $\beta 1$ on spinal cord injury in rats," Neuroscience Letters, vol. 203, no. 2, pp. 97-100, 1996.

[34] W. R. Tyor, N. Avgeropoulos, G. Ohlandt, and E. L. Hogan, "Treatment of spinal cord impact injury in the rat with transforming growth factor- $\beta$," Journal of the Neurological Sciences, vol. 200, no. 1-2, pp. 33-41, 2002.

[35] J. Rogers and L. F. Lue, "Microglial chemotaxis, activation, and phagocytosis of amyloid $\beta$-peptide as linked phenomena in Alzheimer's disease," Neurochemistry International, vol. 39, no. 5-6, pp. 333-340, 2001.

[36] M. D. Ikonomovic, K. Uryu, E. E. Abrahamson et al., "Alzheimer's pathology in human temporal cortex surgically excised after severe brain injury," Experimental Neurology, vol. 190, no. 1, pp. 192-203, 2004.

[37] A. Iwata, X. H. Chen, T. K. McIntosh, K. D. Browne, and D. H. Smith, "Long-term accumulation of amyloid- $\beta$ in axons following brain trauma without persistent upregulation of amyloid precursor protein genes," Journal of Neuropathology and Experimental Neurology, vol. 61, no. 12, pp. 1056-1068, 2002.

[38] K. Uryu, H. Laurer, T. McIntosh et al., "Repetitive mild brain trauma accelerates Abeta deposition, lipid peroxidation, and cognitive impairment in a transgenic mouse model of Alzheimer amyloidosis," The Journal of Neuroscience, vol. 22, pp. 446-454, 2002.

[39] D. J. Loane, A. Pocivavsek, C. E. H. Moussa et al., "Amyloid precursor protein secretases as therapeutic targets for traumatic brain injury," Nature Medicine, vol. 15, no. 4, pp. 377379, 2009.
[40] R. C. Mannix, J. Zhang, J. Park et al., "Age-dependent effect of apolipoprotein E4 on functional outcome after controlled cortical impact in mice," Journal of Cerebral Blood Flow and Metabolism, vol. 31, no. 1, pp. 351-361, 2011.

[41] I. Blasko, R. Beer, M. Bigl et al., "Experimental traumatic brain injury in rats stimulates the expression, production and activity of Alzheimer's disease $\beta$-secretase (BACE-1)," Journal of Neural Transmission, vol. 111, no. 4, pp. 523-536, 2004.

[42] X. H. Chen, R. Siman, A. Iwata, D. F. Meaney, J. Q. Trojanowski, and D. H. Smith, "Long-term accumulation of amyloid- $\beta, \beta$-secretase, presenilin- 1 , and caspase- 3 in damaged axons following brain trauma," American Journal of Pathology, vol. 165, no. 2, pp. 357-371, 2004.

[43] Y. Nadler, A. Alexandrovich, N. Grigoriadis et al., "Increased expression of the $\gamma$-secretase components presenilin-1 and nicastrin in activated astrocytes and microglia following traumatic brain injury," GLIA, vol. 56, no. 5, pp. 552-567, 2008.

[44] Y. F. Liaoi, B. J. Wang, H. T. Cheng, L. H. Kuo, and M. S. Wolfe, "Tumor necrosis factor- $\alpha$, interleukin- $1 \beta$, and interferon- $\gamma$ stimulate $\gamma$-secretase-mediated cleavage of amyloid precursor protein through a JNK-dependent MAPK pathway," Journal of Biological Chemistry, vol. 279, no. 47, pp. 49523-49532, 2004.

[45] W. S. T. Griffin, J. G. Sheng, S. M. Gentleman, D. I. Graham, R. E. Mrak, and G. W. Roberts, "Microglial interleukin- $1 \alpha$ expression in human head injury: correlations with neuronal and neuritic P-amyloid precursor protein expression," Neuroscience Letters, vol. 176, no. 2, pp. 133-136, 1994.

[46] X. H. Chen, V. E. Johnson, K. Uryu, J. Q. Trojanowski, and D. H. Smith, "A lack of amyloid $\beta$ plaques despite persistent accumulation of amyloid $\beta$ in axons of long-term survivors of traumatic brain injury," Brain Pathology, vol. 19, no. 2, pp. 214-223, 2009.

[47] R. O. Sanchez Mejia, V. O. Ona, M. Li, and R. M. Friedlander, "Minocycline reduces traumatic brain injury-mediated caspase- 1 activation, tissue damage, and neurological dysfunction," Neurosurgery, vol. 48, no. 6, pp. 1393-1401, 2001.

[48] N. Bye, M. D. Habgood, J. K. Callaway et al., "Transient neuroprotection by minocycline following traumatic brain injury is associated with attenuated microglial activation but no changes in cell apoptosis or neutrophil infiltration," Experimental Neurology, vol. 204, no. 1, pp. 220-233, 2007.

[49] E. Siopi, A. H. Cho, S. Homsi et al., "Minocycline restores sAPPalpha levels and reduces the late histopathological consequences of traumatic brain injury in mice," Journal of Neurotrauma, vol. 28, pp. 2135-2143, 2011.

[50] A. B. Jaffe, C. D. Toran-Allerand, P. Greengard, and S. E. Gandy, "Estrogen regulates metabolism of Alzheimer amyloid $\beta$ precursor protein," The Journal of Biological Chemistry, vol. 269, no. 18, pp. 13065-13068, 1994.

[51] E. Kojro, G. Gimpl, S. Lammich, W. März, and F. Fahrenholz, "Low cholesterol stimulates the nonamyloidogenic pathway by its effect on the $\alpha$-secretase ADAM 10," Proceedings of the National Academy of Sciences of the United States of America, vol. 98, no. 10, pp. 5815-5820, 2001.

[52] B. S. Kasturi and D. G. Stein, "Progesterone decreases cortical and sub-cortical edema in young and aged ovariectomized rats with brain injury," Restorative Neurology and Neuroscience, vol. 27, no. 4, pp. 265-275, 2009.

[53] B. Li, A. Mahmood, D. Lu et al., "Simvastatin attenuates microglial cells and astrocyte activation and decreases interleukin-1B level after traumatic brain injury," Neurosurgery, vol. 65, no. 1, pp. 179-185, 2009.

[54] H. Wang, L. Durham, H. Dawson et al., "An apolipoprotein Ebased therapeutic improves outcome and reduces Alzheimer's 
disease pathology following closed head injury: evidence of pharmacogenomic interaction," Neuroscience, vol. 144, no. 4, pp. 1324-1333, 2007.

[55] E. E. Abrahamson, M. D. Ikonomovic, C. Edward Dixon, and S. T. DeKosky, "Simvastatin therapy prevents brain traumainduced increases in $\beta$-amyloid peptide levels," Annals of Neurology, vol. 66, no. 3, pp. 407-414, 2009.

[56] D. J. Loane, P. M. Washington, L. Vardanian et al., "Modulation of ABCA1 by an LXR agonist reduces beta-amyloid levels and improves outcome after traumatic brain injury," Journal of Neurotrauma, vol. 28, no. 2, pp. 225-236, 2011.

[57] P. E. Cramer, J. R. Cirrito, D. W. Wesson et al., "ApoE-directed therapeutics rapidly clear beta-amyloid and reverse deficits in AD mouse models," Science, vol. 335, no. 6075, pp. 1503-1506, 2012. 


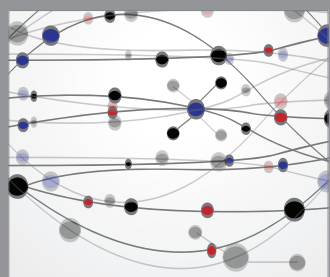

The Scientific World Journal
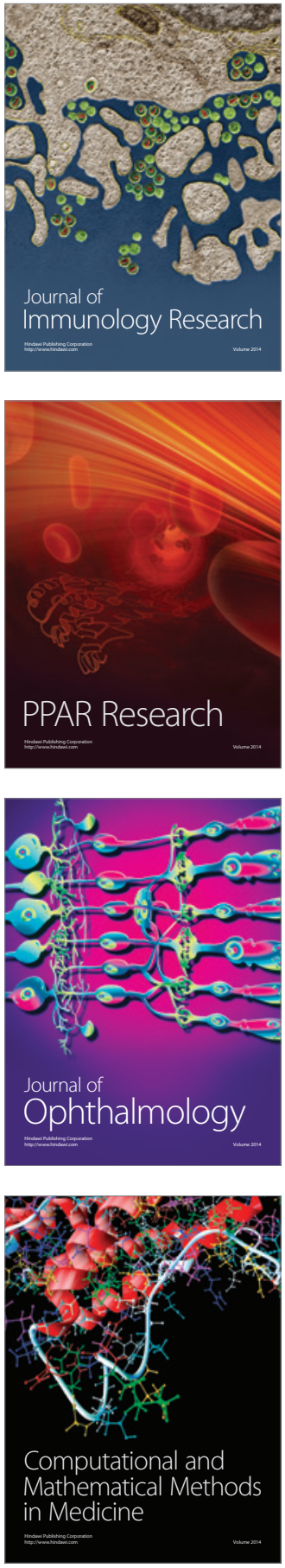

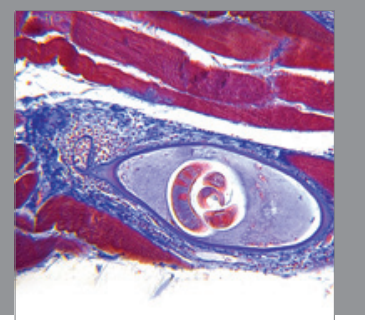

Gastroenterology

Research and Practice
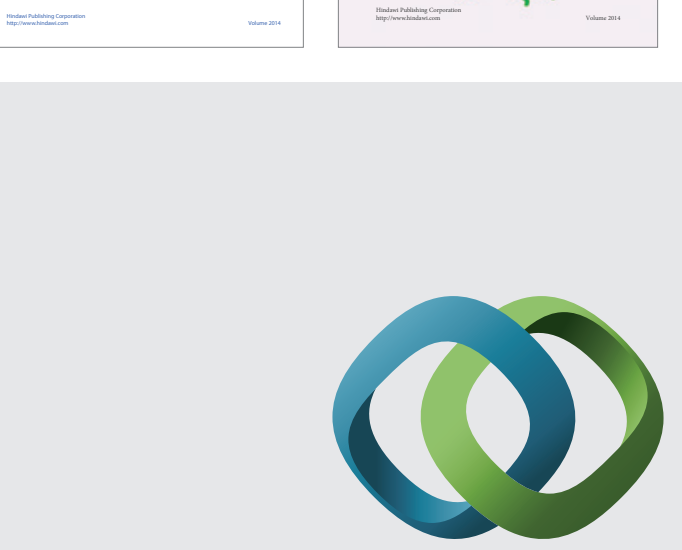

\section{Hindawi}

Submit your manuscripts at

http://www.hindawi.com
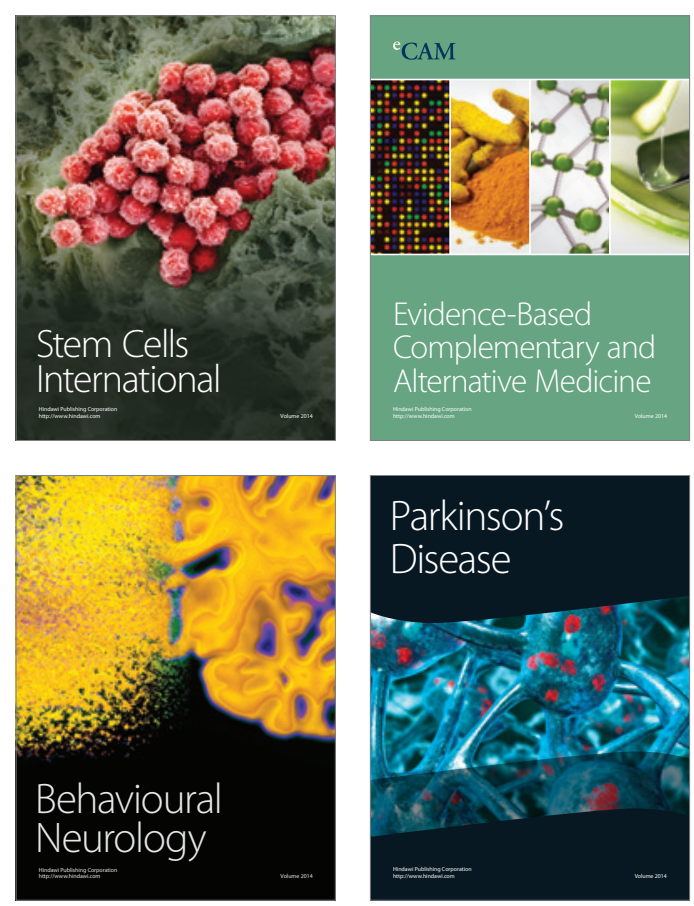

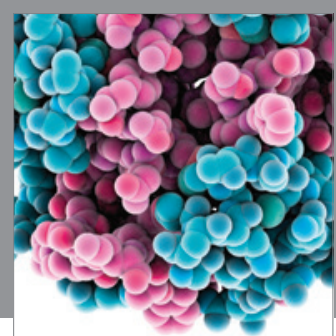

Journal of
Diabetes Research

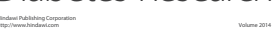

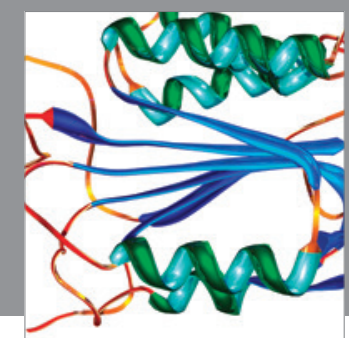

Disease Markers
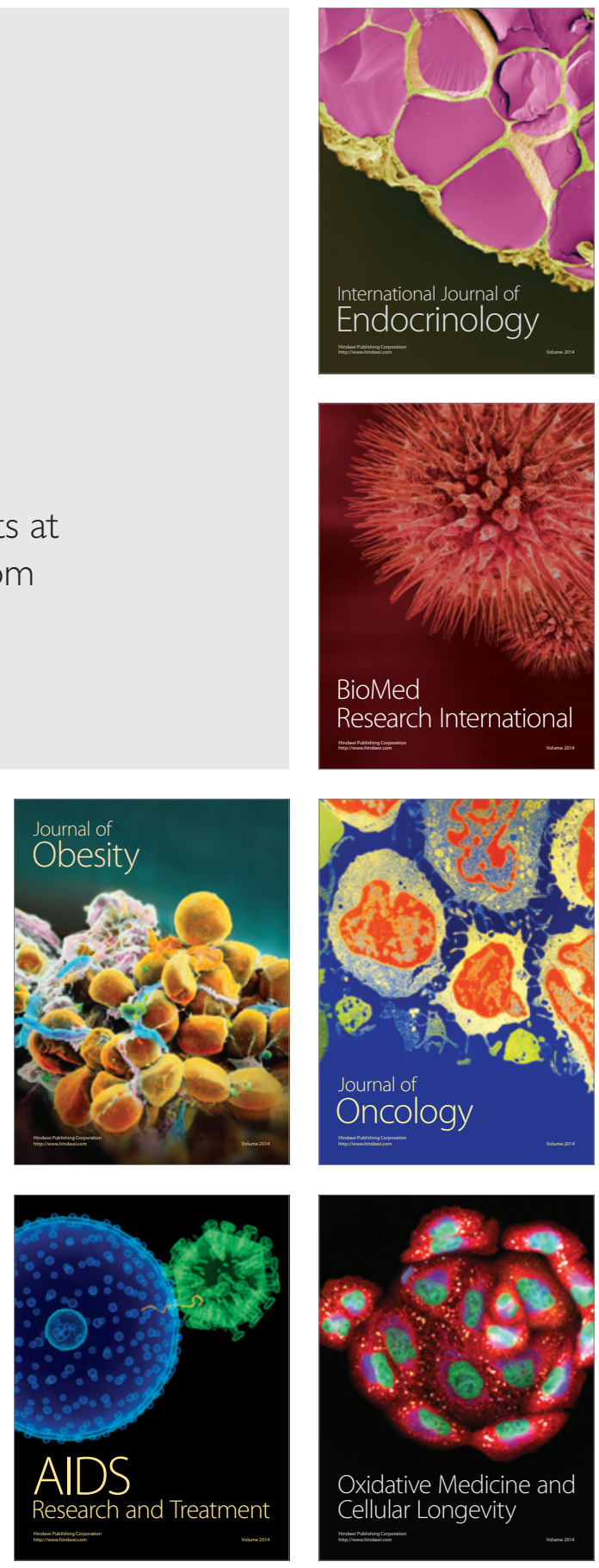